\title{
A Biomedicina ${ }^{1}$
}

KENNETH ROCHEL DE CAMARGO JR. ${ }^{2}$

\section{RESUMO}

A construção teórica de categorias nosológicas desempenha um papel fundamental para a racionalidade médica. Estruturado a partir dos modelos de cientificidade oriundos do desenvolvimento da Física clássica, o saber médico apresenta-se, contudo, como um agregado irregular de disciplinas no qual muitas das noções fundamentais são implícitas, levando ao surgimento de contradições insuperáveis no seu interior e na sua relação com a prática. Este trabalho analisa em detalhe alguns dos pressupostos dessa racionalidade, procurando explicitar os obstáculos que estes produzem para que se alcancem os objetivos éticos da prática terapêutica.

Palavras-chave: Epistemologia; racionalidade médica; história da Medicina. 


\section{Apresentação}

Este trabalho é uma produção teórica vinculada ao Projeto Racionalidades Médicas, coordenado pela professora Madel Luz no Instituto de Medicina Social da UERJ. Nesse projeto, o termo racionalidade médica foi definido operacionalmente como "um sistema lógica e teoricamente estruturado, composto de cinco elementos teóricos fundamentais", quais sejam: a) uma morfologia ou anatomia humanas; b) uma fisiologia ou dinâmica vital humana; c) um sistema de diagnósticos; d) um sistema de intervenções terapêuticas; e e) uma doutrina médica. Além desses elementos constitutivos, é importante também considerar que os fundamentos das racionalidades assim descritas residem numa cosmologia (LUZ, 1992). Note-se que o termo "cosmologia" aqui não se refere à moderna disciplina, ramo da Física, mas a uma perspectiva de ordenação geral daquilo que existe e das formas de apreender este "real", sendo a Cosmologia-disciplina uma decorrência da cosmologia em sentido lato do Ocidente moderno.

Uma das racionalidades estudadas no âmbito desse projeto foi a Medicina Ocidental Contemporânea ou, mais resumidamente, Biomedicina. A opção por esta última denominação deve-se, além de sua maior concisão, ao fato de esta refletir mais adequadamente a vinculação dessa racionalidade com o conhecimento produzido por disciplinas científicas do campo da Biologia, conforme descrito mais adiante. Neste texto, discuto basicamente as linhas gerais do desenvolvimento histórico da Biomedicina, com ênfase no surgimento do conceito moderno de doença, e as implicações desse conceito na sua diagnose e terapêutica.

A Biomedicina vincula-se a um "imaginário científico" correspondente à racionalidade da mecânica clássica, caminhando no sentido de isolar componentes discretos, reintegrados a posteriori em seus "mecanismos" originais. $\mathrm{O}$ todo desses mecanismos é necessariamente dado pela soma das partes - eventuais inconsistências devem ser debitadas ao desconhecimento de uma ou mais "peças". Resumindo, essa racionalidade pode ser delineada em três proposições:

- dirige-se à produção de discursos com validade universal, propondo modelos e leis de aplicação geral, não se ocupando de casos individuais: caráter generalizante;

- os modelos aludidos acima tendem a naturalizar as máquinas produzidas pela tecnologia humana, passando o "Universo" a ser visto como uma 
gigantesca máquina, subordinada a princípios de causalidade linear traduzíveis em mecanismos: caráter mecanicista;

- a abordagem teórica e experimental adotada para a elucidação das "leis gerais" do funcionamento da "máquina universal" pressupõe o isolamento de partes, tendo como pressuposto que o funcionamento do todo é necessariamente dado pela soma das partes: caráter analítico.

\section{A Racionalidade Biomédica: Introdução e Aspectos Históricos}

Na visão analítico-mecanicista delineada acima, e coerente com a mesma, a medicina que se origina a partir da anátomo-clínica é uma medicina do corpo, das lesões e das doenças ${ }^{3}$. É evidente que a incorporação desse referencial à Medicina não se deu de forma mecânica, nem imediata; mesmo com a participação fundamental de Vesálio, por exemplo, na "revolução científica" (HALL, 1988) pela ênfase na observação e na recusa implícita da autoridade dos clássicos (Vesálio teria dedicado vários trechos de seu Humani Corporis à crítica de Galeno), a dominação teórica do galenismo e o conservadorismo das corporações médicas garantiram uma sobrevivência considerável das visões medievais sobre a saúde e a doença. Até finais do século XVIII persiste a visão humoralista do processo de saúde-doença, com seus corolários terapêuticos (sangrias, purgantes, vesicatórios) embora já acrescida de recursos terapêuticos químicos, contribuição fundamental do controverso Paracelso (HALL, 1988, p. 121-122).

A nova ciência, contudo, aponta para a necessidade de uma nova objetividade, incompatível com a caracterização das doenças baseada apenas na sua sintomatologia. Em 1761 surge o De Sedibus, de Morgagni, primeiro passo de uma trajetória que iria modificar radicalmente a face da Medicina no Ocidente. Particularmente na França, onde o trabalho de Morgagni foi extremamente bem acolhido pela comunidade médica (GRMEK, 1991), a perspectiva de encontrar-se a essência da doença a partir do exame empírico de lesões delineia todo um novo campo epistemológico. Essa transição corresponde ao processo, apontado por Foucault em $O$ Nascimento da Clínica, de surgimento da anátomo-clínica.

Essa delimitação não é, evidentemente, a única possível. Clavreul (1983), por exemplo, crê poder situar as raízes do pensamento e da prática médica contemporâneos na escola hipocrática. Entretanto, tomando-se como referencial as dimensões propostas na definição de racionalidade médica, vê-se que a 
incorporação da anatomia patológica ao arsenal técnico-científico da medicina configura uma ruptura de tal importância que justifica a sua adoção como marco. A Medicina do final do século XVIII e a do século XX são muito mais próximas entre si do que de qualquer de seus antecedentes históricos, ainda que possam ter conservado elementos destes.

Todavia, apesar de Foucault atribuir um papel preponderante a Bichat nesse processo, o mais razoável talvez seja perceber uma trajetória bem menos abrupta que, a partir do trabalho inaugural de Morgagni, e passando pelo próprio Bichat, vai encontrar uma expressão ainda mais característica em Laennec e consolidar-se com Virchow. Assim, ao invés de uma transição brusca, operada na passagem do século XVIII ao XIX, teríamos um processo de transformação, também radical, mas mais diluída no tempo, estendendo-se da segunda metade do século XVIII ao final da primeira metade do século XIX (ACKEMECHT, 1986). Nesse processo consolida-se uma das vertentes da caracterização das doenças, que ao fim e ao cabo serão vistas não mais como um fenômeno vital, mas como a expressão de lesões celulares. O mais fundamental aqui, contudo, é a mudança de perspectiva que se opera: a nova concepção de doença passa a ser a categoria central do saber e da prática médica. Parafraseando Luz, a Medicina ocidental se torna, definitivamente, uma ciência das doenças, contrapondo-se, por exemplo, ao projeto hannemanniano de criar uma ciência da "arte de curar".

Esse passo, contudo, não seria possível sem profundas transformações institucionais na prática e no ensino da Medicina, pois a Medicina que se delineia a partir de então é caracteristicamente hospitalar (ACKEMECHT, 1986; FOUCAULT, 1981). É nos hospitais que se poderá reunir, em grande número, as observações necessárias ao estabelecimento das descrições anátomopatológicas; as necrópsias passam a ser efetuadas às centenas. O hospital, na virada do século XVIII, não pode ser considerado ainda uma máquina de tratar, uma vez que os tratamentos eficazes ainda demorarão para ser produzidos; mas certamente já é uma máquina de pesquisa e de ensino.

Decerto que essas transformações não podem ser compreendidas fora do contexto social mais geral onde se desenvolvem. Para Foucault, por exemplo, a importância dos hospitais como local de tratamento deriva da necessidade de recuperar soldados aptos a manejar o fuzil, que já não seriam tão dispensáveis. A importância da Medicina nas cidades só tende a crescer com o processo de migração a partir do campo, na esteira da Revolução Industrial. Isto talvez 
explique, ao menos em parte, por que um dos principais pólos de desenvolvimento da Medicina àquela altura fosse justamente a França.

De qualquer modo, as dimensões da racionalidade médica ocidental estarão, desde então, sempre referidas às doenças. A doutrina médica traz implícita a idéia de que as doenças são objetos com existência autônoma, traduzíveis pela ocorrência de lesões que seriam, por sua vez, decorrência de uma cadeia de eventos desencadeados a partir de uma causa ou de causas múltiplas; o sistema diagnóstico é dirigido à identificação das doenças, a partir da caracterização de suas lesões. A terapêutica é hierarquizada segundo sua capacidade de atingir as causas últimas das doenças; a morfologia e a dinâmica vital servem, sobretudo, como auxiliares na caracterização do processo mórbido. A própria definição de saúde, apesar dos inúmeros esforços em contrário, é assumida como a ausência de doenças.

Tem-se a partir daí um outro traço característico da racionalidade médica ocidental: a perspectiva dual de uma "normalidade" caracterizada por sua oposição à "patologia", relação magistralmente caracterizada por Canguilhem (1982). A característica mais peculiar, contudo, talvez seja a de relegar para um terreno de implícitos todas essas definições. Enquanto outras racionalidades têm códices bastante explícitos no que tange aos seus princípios gerais, na Medicina ocidental eles podem apenas ser inferidos a partir do exame do seu discurso e de sua prática (CAMARGO JR., 1990). Aqui também creio poder mencionar outro ponto de convergência com a racionalidade científica mais abrangente, ao menos na sua versão clássica. Como essas definições não são empiricamente deriváveis, a visão positivista tenderá a deixá-las de lado, uma vez que o seu terreno seria o da metafísica, e não o da ciência. Isto não seria, em si, um problema, não fosse o fato de que essas concepções, bastante presentes na investigação e na atuação médicas, não quedassem além de qualquer crítica, com os riscos que Burtt apontou em relação à metafísica oculta do positivismo:

"Por esta razão, há um perigo extremamente sutil e insidioso no positivismo se não se pode evitar a metafísica, que tipo de metafísica provavelmente cultivará a pessoa que se sinta suficientemente livre da abominação? É claro que, não é necessário dizer, neste caso sua metafísica será mantida acriticamente, porque é inconsciente; além disso, será passada adiante a outros bem mais rapidamente do que as suas outras noções, uma vez que será propagada por insinuação, em vez do argumento direto. Um testemunho extremamente interessante da penetrante influência da filosofia newtoniana, 
ao longo do curso do pensamento moderno, é a incapacidade de um estudante sério de Newton ver que seu mestre possuía uma metafísica das mais importantes" (BURTT, 1983, p. 181).

É claro que a acepção de cada um daqueles termos muda em algum grau em função de modificações mais amplas no conhecimento médico. Vejam-se as concepções de causa, por exemplo: os primeiros anátomo-patologistas recusavamse a especular sobre as causas do adoecer, julgando-as impossíveis de se conhecer. Mais tarde, com o desenvolvimento da Microbiologia, num primeiro momento se supôs que praticamente todas as doenças seriam fruto da atividade de microorganismos. Atualmente, assiste-se a uma certa reedição dessa perspectiva teórica a partir da Biologia molecular, segundo a qual o mapeamento genético possibilitaria reconhecer - e curar - qualquer doença, ou quase. Mas mesmo na mudança há permanência.

Poucas noções terão sido tão fundamentalmente alteradas quanto a de lesão. Para os primeiros anátomo-patologistas, as lesões eram teciduais, e o uso do microscópio era veementemente recusado (ACKEMECHT, 1986). A partir de Virchow, a patologia é caracteristicamente celular; Garrod aponta para um erro inato do metabolismo como sendo a característica-chave da alcaptonúria, na virada do século (neste caso, tem-se uma lesão e uma causa, coincidentes num certo sentido). Mais tarde, Pauling irá demonstrar que a lesão da falcemia é uma alteração química da hemoglobina. Ao mesmo tempo, em todas as definições que se sucedem, há sempre a perspectiva comum da tradução objetiva do ser da doença.

Os ganhos tecnológicos mais avançados são incorporados constantemente ao acervo fenômeno técnico ${ }^{5}$ das várias disciplinas médicas, porém sempre submetidos à racional idade mecânico-causal já descrita. $\mathrm{O}$ corpo humano visto pela Medicina é dividido em sistemas, agrupados segundo as propriedades isoladas por cada uma das disciplinas articuladas em seu discurso. Outra característica importante do saber médico é a divisão entre "normal" e "patológico", divisão esta que é operativa, e não conceitual (CANGUILHEM, 1992). Essa divisão também se reflete na organização do saber médico, no qual por vezes (embora não necessariamente) se formam pares de disciplinas homólogas divididas pela pertinência aos domínios da "normalidade" ou da "patologia". Exemplo típico é dado pelo par Fisiologia/Fisiopatologia.

O corpo humano se divide, nesta racionalidade, numa série de sistemas com funções bem definidas, divisão que é parte morfológica, parte funcional, com 
prioridade para esta última. Alguns sistemas são subdivididos, como o sistema nervoso, que pode ser repartido em sistema nervoso central e sistema nervoso autônomo, cada um com funções específicas, ainda que interligadas. Tal característica, a interligação, é atribuível a todos os sistemas, na medida em que necessariamente fazem parte de uma mesma totalidade orgânica, e mostra o grau de arbitrariedade inerente a qualquer divisão desse tipo.

As chamadas "disciplinas básicas" do ponto de vista da Biomedicina, como a Fisiologia, a Fisiopatologia e a Bioquímica, e possivelmente a Genética, aquelas que, dentro do campo médico, são as mais diretamente relacionadas ao método experimental, têm alguns conceitos genéricos fundamentais no desenho dessa racionalidade. O primeiro é a noção de um meio interno, microambiente corporal isolado do resto do universo por barreiras epiteliais (pele e mucosas). A manutenção das condições de funcionamento desse microambiente dentro de limites estreitos de tolerância denomina-se homeostase. Os processos diretamente relacionados com a manutenção dessa constância interna, comuns a todos os seres vivos, são coletivamente denominados vida vegetativa, e os processos de interação voluntária com o resto do ambiente são, por sua vez, chamados de vida de relação. A utilização da palavra vida aqui não tem qualquer conotação ontológica, podendo ser traduzida por "modo de funcionamento do organismo", da forma mais mecânica possível. Outro conceito importante é o de metabolismo, visto como o conjunto de reações (bio)químicas que se dão no organismo.

A visão de funcionamento orgânico que emerge dessas disciplinas é fortemente ligada à teoria de sistemas. Assim, a manutenção da homeostase é vista como função de um conjunto de mecanismos regulatórios baseados em laços de retroalimentação (feed-back loops). Essa visão cibernética, contemporânea de outras ciências, coabita com a racionalidade descrita anteriormente no âmbito dessas disciplinas. Na prática médica, porém, predomina a segunda.

Há um grande grau de correspondência entre a divisão dos sistemas e a divisão em especialidades da própria Medicina. Assim, o sistema respiratório é território dos pneumologistas; o gastrintestinal, dos gastroenterologistas e o sistema nervoso central, dependendo do ângulo que se tome, é dos neurologistas ou dos psiquiatras. Essa divisão territorial não é regra, na medida em que existem especialidades clínicas e cirúrgicas que respondem por um mesmo espaço; de todo modo, a organização em sistemas é também uma organização do saber 
médico. Várias taxonomias se cruzam nesse campo do saber, superpondo-se de forma imperfeita e dando origem a várias inconsistências. O maior exemplo destas é dado pelo grande catálogo de doenças utilizados por médicos em todo o mundo - a Classificação Internacional de Doenças (CID). O critério de agrupamento de sua primeira divisão é etiológico (I - doenças infecciosas e parasitárias); o da segunda é anátomo-clínico (II - neoplasmas); os das seguintes são morfofuncionais (III) - transtornos das glândulas endócrinas, da nutrição e do metabolismo e transtornos imunitários; e IV - doenças do sangue e dos órgãos hematopoiéticos ${ }^{6}$ ); o da próxima é filosófico ( $\mathrm{V}$ - transtornos mentais) e assim por diante, numa classificação que lembra muito o bestiário criado por Borges, citado por Foucault no início de As Palavras e as Coisas.

As várias disciplinas que se entrecruzam na prática médica não são articuladas no âmbito teórico-conceitual, mesmo porque o corpo conceitual fundamental dessa prática é, em larga medida, implícito. A articulação dos saberes entre si e destes com a prática é fluida, o que faz com que a prática médica possa ser vista, neste particular, como um interminável exercício de criação de ideologias científicas, tal como foram descritas por Canguilhem (1977, p. 41): "sistemas explicativos cujo objeto é hiperbólico, relativamente à norma de cientificidade que eventualmente lhe é aplicada". A relação entre teoria e prática, portanto, não é de determinação; embora as formulações teóricas sejam fundamentais do ponto de vista da legitimação social jurídica, política, cultural) da prática médica, o papel exercido pela teoria no exercício profissional é contingente. Mais ainda, a congruência das várias formulações disciplinares é também incompleta, daí resultando que formulações explicativas divergentes, irredutíveis umas às outras, estejam disponíveis para um mesmo evento. Frente a uma doença infecciosa, por exemplo, pode-se conceder preponderância à ação de microorganismos ou à resposta imunitária do hospedeiro (no caso, o homem). Muito embora a idéia de "multicausalidade" seja freqüentemente proposta como modelo explicativo ${ }^{7}$, os modelos de causalidade linear predominam na prática (quando alguma causa é postulada), fazendo com que discursos disciplinares tidos como complementares acabem por se tornar concorrentes.

Disto tudo resulta que a prática médica recorre com surpreendente flexibilidade ao seu arsenal teórico, muitas vezes prosseguindo sem teoria nenhuma, sem que isto represente necessariamente um menor rigor profissional ou menos ainda uma perda da qualidade - e da eficácia - do exercício profissional (CAMARGO JR., 1990, p. 110-111). Outra consequiência importante - agora do ponto de vista teórico - da fluidez teórico-conceitual apontada é que as 
eventuais "rupturas" epistemológicas não implicam necessariamente superação, abandono do saber "velho". Remanescentes de etapas historicamente anteriores coexistem com o contemporâneo no interior do saber médico; em mais de um sentido as teorias microbianas do adoecer resgatam as noções ontológicas das doenças, por exemplo. Essa característica é observada ainda, no fato, apontado no início desta seção, de que aquilo que poderíamos chamar de imaginário científico da Medicina contemporânea se enraíza na Física clássica (mecanicismo, causalidade linear) e não nos desenvolvimentos já nem tão recentes desta disciplina, em que pese o equipamento médico ter incorporado em larga escala as conquistas da mecânica quântica, por exemplo ${ }^{8}$.

\section{Doutrina Médica: Características Fundamentais}

Esta doutrina é basicamente implícita. A atividade profissional e o próprio referencial teórico da Medicina não dispõem de um "fio condutor" claramente enunciado. Do ponto de vista da formalização, um arremedo de "doutrina" é dado por alguns aforismos, às vezes em latim, com os quais esbarramos freqüientemente ao ler manuais de Medicina, tais como: "não há doenças, e sim doentes" (dito que, na prática, não tem qualquer repercussão), "primum non nocere” etc. Não há ideais ético-normativos explícitos que guiem o médico, com a possível exceção da legislação deontológica da atividade profissional, que, todavia, não é, em hipótese alguma, uma instância de articulação teóricoconceitual. Essa situação não é propriamente uma surpresa, na medida em que praticamente todas as noções fundamentais da medicina (como doença, saúde, cura e até mesmo homem, no sentido de ser humano) são igualmente implícitas.

Outra característica importante, ao menos como prática discursiva, é a alusão recorrente a três domínios teóricos que são a suposta tradução da "totalidade do homem": Biologia, Psicologia e Sociologia. A pretensa totalidade é usualmente expressa condensando-se todos os termos em um só biopsicossocial - como se a mera justaposição de discursos pudesse, por si só, abolir a fragmentação inerente ao próprio modelo de desenvolvimento disciplinar característico da modernidade. Agregue-se a isto o fato de que os termos "psico" e "social" não passam de referências genéricas, subordinadas ao primado do discurso biológico (CAMARGO JR., 1990).

Há, todavia, uma espécie de "doutrina da não-doutrina”, um suporte comum não enunciado que se apóia, por um lado, na forma consensual de 
exercício da prática médica e, por outro, num grupo de representações que desempenha o papel que se esperaria de uma doutrina geral.

Tais representações são, no seu conjunto, coerentes com a cosmologia mecanicista que alicerça, ainda que de modo dissimulado, o saber médico. A dificuldade com esse grupo de representações é que ele não se encontra explicitado em nenhum lugar, embora seja ubíquo. Pode-se percebê-lo claramente nas entrelinhas do saber médico; pode-se entrevê-lo quando um professor de Medicina ensina. Num certo sentido, pode-se dizer que constituem a espinha dorsal da "ciência médica". Esse grupo de representações poderia ser resumido num número bem pequeno de proposições, tais como: "as doenças são coisas, de existência concreta, fixa e imutável, de lugar para lugar e de pessoa para pessoa; as doenças se expressam por um conjunto de sinais e sintomas, que são manifestações de lesões, que devem ser buscadas por sua vez no âmago do organismo e corrigidas por algum tipo de intervenção concreta".

O termo "concreta" aqui refere-se às terapêuticas medicamentosas e cirúrgicas, mais valorizadas pelos médicos de um modo geral. Essas proposições, que formam uma espécie de "teoria das doenças", não se encontram em lugar nenhum, mas dificilmente soariam estranhas a qualquer médico. Não sendo explicitadas, não podem ser confrontadas, dissecadas. Não sendo discutidas, impregnam cada palmo da atividade médica, sem se submeter aos cânones do dogma científico. Tais representações se transformam numa espécie de "corpo teórico" paracientífico, com um conjunto de categorias próprias. Paradoxalmente, a experiência individual do médico é extremamente valorizada. A tensão entre as intenções generalizantes da "teoria médica" e a prática individualizada é apenas mais um exemplo das incontáveis contradições que permeiam o campo da Medicina.

Uma vez que a noção de doença ocupa posição central nesta doutrina, sua definição será abordada em detalhe numa seção específica; antes, contudo, é necessário assinalar a importância que uma disciplina em especial tem nesse campo: a Epidemiologia. A discussão sobre a racionalidade epidemiológica não será abordada aqui; contudo, basta assinalar que as questões básicas concernentes à articulação entre as duas disciplinas (Clínica e Epidemiologia) se referem à caracterização genérica de uma dada doença e do estabelecimento de nexos causais entre doenças e possíveis agentes etiológicos. Apesar da pujança metodológica da Epidemiologia, a produção de conhecimento por esta disciplina encontra-se subordinada à Clínica, no momento da definição das 
doenças (ou "desordens-alvo"), e às Ciências Biológicas, no estabelecimento e/ou corroboração de hipóteses etiológicas.

Creio que é neste sentido que Naomar de Almeida Filho (1987, p. 17) afirma que a teoria da doença é propriedade da Clínica, ainda que reconhecendo o papel da Epidemiologia na sua construção. Dadas essas subordinações, me parece justificada a inclusão da Epidemiologia como parte da racionalidade da Medicina ocidental contemporânea, subordinando-se, portanto, à mesma cosmologia mecanicista que impregna o imaginário científico desta.

\section{A Estrutura da Doença}

Do ponto de vista da formalização teórica, a versão mais aperfeiçoada de um modelo descritivo de doenças em geral é o denominado por seus autores (LEAVELL e CLARK, 1976, p. 14-35) de História Natural das Doenças. As críticas a esse modelo são múltiplas, e não pretendo repeti-las. A eventuais objeções de que se trata de uma formulação antiga, responderia apenas que, não tendo surgido nada que a suplante, esta parece continuar servindo de embasamento a toda uma série de construções na Biomedicina, como pode ser verificado com o mero folhear de qualquer manual médico, por mais contemporâneo que seja. Apresento a seguir uma adaptação do esquema de Leavell e Clark (1976), sugestivamente denominado pelos autores de "História Natural de Qualquer Processo Mórbido no Homem".

Há vários aspectos dignos de nota neste pequeno esquema: percebase, por exemplo, que enquanto o eixo das abscissas é claramente cronológico e quantitativo, o das ordenadas parece intentar representar também de forma quantitativa o processo saúde/doença - no caso, um deslocamento para cima significaria uma "maior quantidade de doença", sendo a quantidade máxima de doença representada pela morte. Outro aspecto fundamental diz respeito à descrição de doenças como processos com causas definidas - ainda que múltiplas - com um transcurso temporal predeterminado. 


\section{História Natural das Doenças}

(Segundo Leavell e Clark)

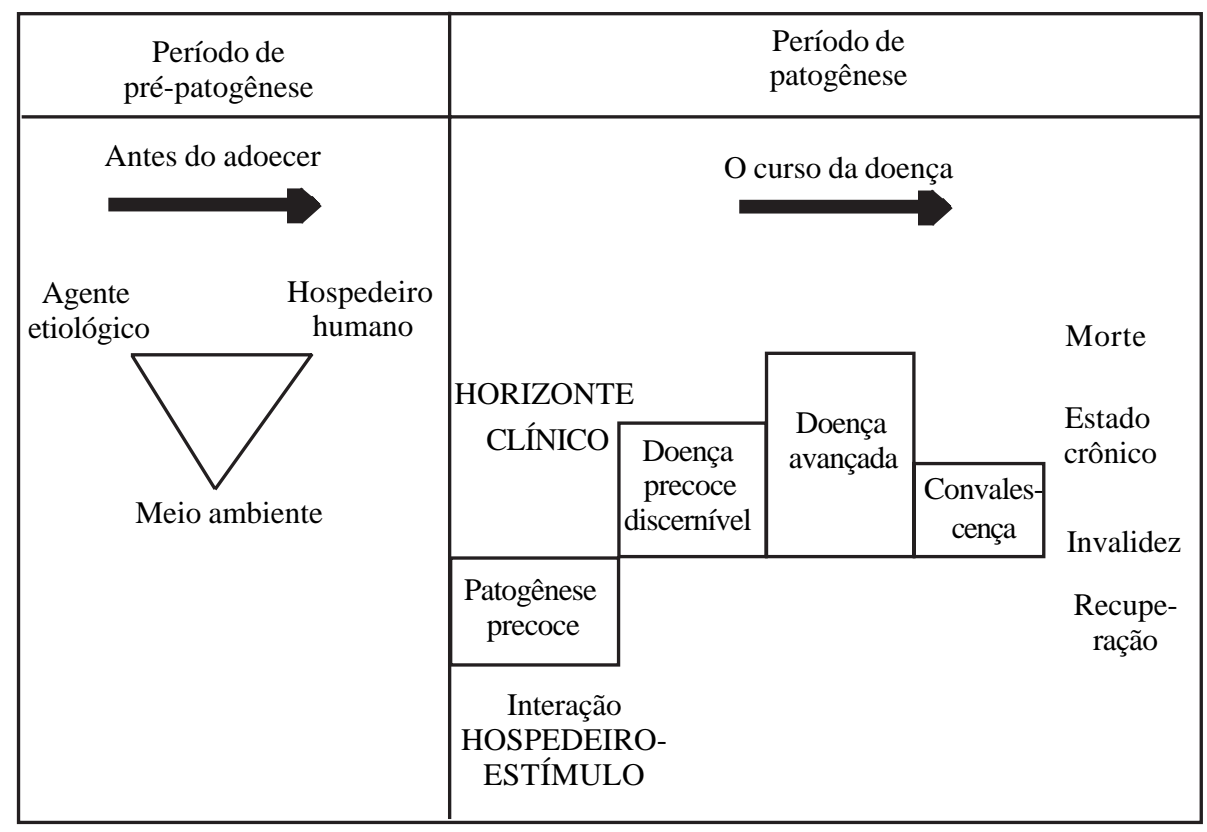

O que é importante para os fins desse texto, contudo, é assinalar que ele encerra, segundo seus autores, toda a lógica da intervenção médica: evitar ou retardar a progressão de doenças ou minimizar o dano por elas causado.

No entanto, mesmo esse modelo, apesar de descrever o "ciclo de vida" das doenças, não esclarece o que viria a ser uma dessas criaturas. De fato, não há, no contexto do saber médico, uma conceituação geral do que seria uma doença, mas ainda assim é possível identificar um arcabouço genérico de construção discursiva dos elementos dessa categoria, constituído por três dimensões ou eixos: o explicativo, o morfológico e o semiológico, apresentados sinteticamente no quadro a seguir. 


\section{Estrutura das Doenças \\ Quadro Sinóptico}

\begin{tabular}{|c|c|c|c|}
\hline & Eixo Explicativo & Eixo Morfológico & Eixo Semiológico \\
\hline Disciplina-tipo & Fisiopatologia & Anatomia patológica & Clínica \\
\hline Categoria Central & Causa & Lesão & Caso \\
\hline Definição de Doença & Processo & $\begin{array}{c}\text { Expressão de } \\
\text { lesão(ões) }\end{array}$ & Gestalt semiológica \\
\hline Método Característico & Experimental & Descritivo & $\begin{array}{c}\text { Indiciário/ } \\
\text { observacional }^{9}\end{array}$ \\
\hline Período Histórico & $\begin{array}{l}\text { Segunda metade } \\
\text { século XIX }\end{array}$ & $\begin{array}{l}\text { Fim século XVIIII } \\
\text { início século XIX }\end{array}$ & Século XVIII \\
\hline
\end{tabular}

Essa descrição toma as doenças como formações discursivas, na acepção de Foucault $\left(1972\right.$, p. 62) ${ }^{10}$, e não objetos preexistentes, já que um dos objetivos deste trabalho é justamente proporcionar uma visão crítica desta pressuposição de preexistência. Note-se que ao utilizar o termo "estrutura", refiro-me apenas ao arranjo de determinadas construções teóricas, não havendo nenhuma pretensão ontológica nesse uso.

O primeiro eixo corresponde à caracterização das doenças como processo, possuindo uma ou mais causas e uma história natural. Este é o eixo da fisiopatologia, da experimentação em animais, com indução de doenças artificiais. É nesse eixo que o saber médico mais se aproxima das ciências "duras" no domínio do biológico. Há ainda alguma relação com a Epidemiologia, no que diz respeito ao estabelecimento de causas. Este é, por fim, o eixo historicamente mais recente, tendo-se desenvolvido a partir da segunda metade do século XIX ${ }^{11}$.

O segundo eixo é o da descrição de lesões características, patognomônicas, território característico da anatomia patológica. O conceito de lesão sofreu modificações basicamente em termos de sua abrangência, acompanhando, como já descrevi anteriormente, o movimento geral das disciplinas biológicas em direção ao microscópico; contemporaneamente descrevem-se lesões em nível molecular. Assim sendo, toda a parafernália laboratorial utilizada para a realização dos chamados exames complementares estaria 
incluída nesse eixo, visto que tais exames dirigem-se, basicamente, a evidenciar lesões. Historicamente esse eixo se consolida num período que vai do final do século XVIII aos primeiros anos do século XIX.

O terceiro e último eixo é o da Clínica propriamente dita, no qual as doenças são vistas como constelações de sinais e sintomas, formando gestalts semiológicas. Este é o eixo da leitura do caso. A caracterização desse eixo no presente não é uma tarefa simples, tendo em vista a imbricação das definições propriamente semiológicas das doenças com os outros dois eixos. Deve-se recordar, porém, que a grade nosológica hoje representada pela classificação contida no Código Internacional de Doenças (CID) data de antes dos desenvolvimentos metodológicos contidos nos eixos anteriores. Se, por um lado, utilizando a terminologia foucaultiana, podemos dizer que a Medicina das espécies foi suplantada pela anátomo-clínica, isto não equivale a dizer que a Medicina tenha deixado de ser classificatória.

Ao contrário, no terreno preparado pela taxonomia anteriormente desenvolvida, ainda no século XVIII, é que as instâncias de objetivação desenvolvidas a partir da anátomo-clínica encontraram um campo de desenvolvimento pleno. Fica claro, portanto, que esse eixo comporta um desenvolvimento simultâneo em duas direções: a da individualização, recorrendo a um método indiciário (tal como descrito por Ginzburg) para recortar uma gestalt semiológica específica. Ao mesmo tempo, há um movimento de generalização, localizando o caso individual num inventário de doenças (a grade nosológica a que aludi há pouco) produzido segundo o mesmo método. É nesta segunda direção que a Clínica se aproxima da Epidemiologia. Mais ainda, se tomarmos Epidemiologia, numa definição mínima, como o estudo de doenças em populações, Clínica e Epidemiologia tornam-se indistinguíveis. Atrevo-me a dizer que, se abstrairmos o instrumental matemático incorporado pela última neste século, as duas disciplinas se confundem nas suas origens: o nascimento da clínica foi, também, o nascimento da Epidemiologia ${ }^{12}$. A separação das duas disciplinas, iniciada posteriormente, ainda hoje é incompleta. Gêmeas xifópagas, Clínica e Epidemiologia encontram-se ligadas por seu patrimônio comum: a coleção de doenças, construída em conjunto pelas duas.

A ordem de apresentação dos três eixos neste texto não é casual. Com efeito, eles estão dispostos segundo a hierarquia valorativa de sua "cientificidade", uma vez que é precisamente esta cientificidade que empresta legitimidade social à Medicina ocidental. Deste ponto de vista, o eixo explicativo é o mais 
valorizado, devido à sua inclusão no domínio das ciências experimentais, e o eixo semiológico, mais próximo da prática - e portanto da "arte" - é relativamente depreciado como método de produção de conhecimento, ficando o eixo morfológico num patamar intermediário. No momento do exercício concreto do ofício de médico, contudo, essa relação hierárquica se inverte, predominando precisamente o eixo menos valorizado do ponto de vista da legitimação social mais uma vez observa-se o divórcio entre a ciência das doenças e a arte de curar.

\section{Diagnose}

Numa primeira aproximação, a operação da diagnose na biomedicina pode ser dividida em dois tipos, denominados de anamnese e exame físico. A primeira consiste no recolhimento da história do paciente, com um roteiro padronizado que passa pela anotação de alguns dados de identificação e sociodemográficos (profissão, idade, cor, entre outros), seguidos da identificação da queixa (ou queixas) presentes do paciente, passando, a seguir, a uma cronologia e contextualização destas: a ordem em que os sintomas surgem, sua relação entre si e com outros eventos, adoecimentos anteriores, doenças presentes na família.

O segundo momento pode ser, por sua, vez subdividido em semiologia "armada" (isto é, que faz uso de exames complementares) e "desarmada", dependente apenas do próprio médico (ainda que com uso de alguns instrumentos simples, como estetoscópio, termômetro, esfigmomanômetro e outros). A primeira é extremamente variada e complexa, e uma abordagem detalhada do instrumental diagnóstico de uso corrente demandaria um trabalho voltado especificamente para este fim. Creio ser suficiente assinalar que, do ponto de vista de uma lógica mais geral, não tem nenhuma especificidade com relação aos outros métodos, além da utilização da alta tecnologia. Agregue-se a isto que, por sua aparência de "ciência concretizada", são mais valorizados como mais "objetivos"; ainda assim, sujeitos que estão no processo de interpretação dos seus resultados, incorporam-se à racionalidade em questão. Os exames complementares vêm crescendo gradualmente em importância, ameaçando tomar a Semiologia uma arte perdida ${ }^{13}$. Não obstante, ainda que realizado de forma esquemática, o exame tal como descrito a seguir marca o início do contato com o paciente, e determina até certo ponto as escolhas que virão a seguir, 
inclusive em termos de exames complementares, justificando uma análise um pouco mais detida das suas etapas.

O exame físico orienta-se espacialmente pela anatomia topográfica do corpo humano, dividido em algumas regiões (cabeça e pescoço, tórax, abdome, membros superiores e inferiores) e sistemas (aparelhos respiratório e cardiovascular). Para cada área espacial há um conjunto de procedimentos a serem executados seqüencialmente: inspeção, percussão, palpação e ausculta. $\mathrm{O}$ exame físico compreende ainda a verificação de valores numéricos, como a temperatura corporal, a pressão arterial e a frequiência do pulso, coletivamente denominados sinais vitais.

Numa divisão esquemática, pode-se dizer que a anamnese se ocupa dos sintomas e o exame físico dos sinais; entre os dois extremos temos um tipo de exame que não corresponde exatamente a nenhum deles: o exame psíquico. Com este é executado quase que exclusivamente por psiquiatras, não será detalhado aqui.

Apesar de os manuais de Semiologia preconizarem um exame exaustivo, esquadrinhando cada parte do corpo, raramente isto ocorre na prática, sendo o procedimento bem mais sumário e orientado por hipóteses diagnósticas, como já afirmei em outra parte ${ }^{14}$.

O objetivo geral da diagnose é a caracterização de doenças, se possível da forma mais minuciosa, detalhando-se todas as lesões presentes e sua evolução temporal, idealmente chegando às suas causas originais (etiologia). No diagrama da história natural das doenças, a diagnose operaria na área acima do chamado "horizonte clínico", quando as manifestações mórbidas já são perceptíveis. O raciocínio clínico se encarregaria de distribuir os dados encontrados ao longo do tempo, na tentativa de reconstruir a evolução cronológica da doença presumida. A evidenciação de lesões pode se dar por vários critérios, remetendo habitualmente à idéia de "normalidade", opondo-se logicamente a esta:

- anomalias: presença de algo que "não deveria estar lá"; como exemplo, a palpação de massas sólidas em locais do abdome onde não são palpáveis na maior parte das pessoas, ou produção de um som timpânico na percussão do tórax;

- distorções: alterações no resultado de algum exame, como variações na forma de onda produzida pelos pulsos periféricos, ou no aspecto anatômico de alguma região, como o desvio cubital das mãos na artrite 
reumatóide, ou ainda alterações na qualidade do som produzido pelos batimentos cardíacos (bulhas);

- supressões: quando algum evento deixa de ser observado, como a abolição de certos reflexos ou o silenciamento dos sons do funcionamento intestinal (ruídos peristálticos);

- variações quantitativas: observadas nos sinais vitais, na semiologia desarmada, ou nos exames complementares que produzem resultados numéricos.

Deve-se ressaltar aqui que essas "constatações" só são possíveis porque cotejadas com uma "normalidade" ideal, o pano de fundo contra o qual são contrastadas. Neste contexto, além da extensa discussão que o já citado Canguilhem faz das relações entre o normal e o patológico, ganha relevância o modelo epistemológico proposto por Fleck (1979; LOWY, 1994) por sua referência ao coletivo de pensamento ${ }^{15}$ (Denkkollektiv) e ao estilo de pensamento ${ }^{16}$ (Denkstil); o segundo determina para os integrantes do primeiro todo o enquadre cognitivo de suas investigações, debates e polêmicas. É o estilo de pensamento, a um tempo organizador e produto da organização de um coletivo de pensamento, que define o que são fatos, artefatos e "anomalias", o que é objetivo ou ilusório, quem é cientista ou "irracional". Enfatizo este ponto porque, dado o caráter implícito da doutrina biomédica, já apontado diversas vezes neste texto, seu papel na determinação dos dados (assim como os fatos da ciência, que Fleck analisa) não é percebido, mascarado pela pretensa empiria radical da semiologia, ilusão que as técnicas de exame complementar só vêm a reforçar ${ }^{17}$.

A disciplina central aqui é a Clínica, que opera a produção de diagnósticos pela referência de quadros sindrômicos (conjuntos de sinais e sintomas) a uma grade diagnóstica, em tese por dois movimentos separados, que denominei anteriormente de leitura e enquadramento. Na prática, há uma grande interpenetração das duas operações, na medida em que hipóteses diagnósticas são formuladas praticamente desde o primeiro momento, guiando toda a operação de coleta de dados, levando à seleção de queixas e à orientação da anamnese e do exame físico ao esclarecimento e discriminação das hipóteses aventadas. A construção das categorias diagnósticas é um empreendimento conjunto da Clínica e da Epidemiologia, embora presas ambas a um mútuo desconhecimento.

O momento da diagnose é o que mais se enquadra no que Ginzburg (1989) denominou de paradigma indiciário: um modo de produção de 
conhecimentos que se concretiza na individualização de singularidades a partir de indícios recolhidos de forma não-sistemática.

Há uma valorização relativa pela corporação dos procedimentos diagnósticos quando comparados com a terapêutica, em especial dos casos "difíceis", das doenças raras, quando a identificação do "diagnóstico correto" é tida como uma prova de grande conhecimento teórico. Talvez por isso, nem sempre o estabelecimento de hipóteses diagnósticas obedece a critérios de probabilidade (i.e., considerar primeiramente as doenças mais freqüentes), partindo, ao invés disso, das doenças mais raras e seguindo um procedimento de exclusão até chegar-se a um diagnóstico. Nas situações em que isto não ocorre, o que é freqüente no atendimento ambulatorial, o processo de solicitação de exames parece também prosseguir indefinidamente ${ }^{18}$. É digno de nota ainda que os casos em que o diagnóstico não é claro são tratados como se fossem atípicos, mesmo representando uma parte considerável da demanda ambulatorial.

\section{Sistema de Intervenção Terapêutica}

Paradoxalmente, a terapêutica desenvolve-se por caminhos nem sempre superpostos aos da diagnose, e sua importância decresce do ponto de vista acadêmico (ALMEIDA, 1988; SAYD, 1995). Isto aponta para outro traço constitutivo da racionalidade médica ocidental, o descompasso entre o projeto científico do estudo das doenças e o projeto ético da terapêutica, nem sempre conciliáveis de todo entre si. Isto se reflete ainda no hiato histórico entre dois marcos consensuais: o do surgimento da Medicina moderna, na já citada transição do século XVIII para o XIX, e o do início da terapêutica moderna, com a síntese do Salvarsan por Erlich já neste século (SAYD, 1995).

Não é possível evidenciar princípios gerais de orientação para a intervenção nesta racionalidade, ao contrário da homeopatia, por exemplo. A terapêutica é definida para cada uma das doenças inventariadas, e pode ser tão variável quanto o número de itens nesse catálogo. Embora teoricamente várias técnicas de intervenção devam ser utilizadas, na prática apenas medicamentos e cirurgias são considerados, via de regra, como terapêutica real. É digna de nota a inexistência da disciplina de terapêutica em várias escolas médicas, $o$ que abre um grande espaço à ação dos propagandistas da indústria farmacêutica. A Farmacologia, por sua vez, tem usualmente uma abordagem mais próxima da Fisiologia, colocando-se ao lado das disciplinas básicas, e não das aplicadas, não desempenhando usualmente as funções da primeira. 
Outras técnicas de intervenção - dietas, exercícios etc. - embora descritas nos manuais, não têm o mesmo status teórico que a terapêutica mais "dura", o que pode se evidenciar pelo pouco apuro com que são prescritas, mesmo porque usualmente se supõe que os pacientes não as irão seguir.

A intervenção coletiva - via Medicina preventiva - pode ser remetida ao mesmo referencial teórico (Rodrigues, 1979, p. 83-89). Além disso, como suas ações estão voltadas para a prevenção de doenças, não se encaixam, por definição, no conceito de terapêutica.

Do ponto de vista dos procedimentos executados, é possível identificar na Biomedicina os seguintes grupos de técnicas terapêuticas:

- Medicamentosa, executada através da administração de um ou mais fármacos em um número variado de apresentações e vias de introdução no organismo;

- Cirúrgica, implicando a manipulação direta de partes do corpo;

- Física, que utiliza procedimentos como exercícios, exposição a radiações de diversos tipos, massagens;

- Dietética.

As duas primeiras têm usualmente maior valorização entre os profissionais, até porque são domínios exclusivos dos médicos (a terapia física é compartilhada com os fisioterapeutas e a dietética com os nutricionistas, numa convivência nem sempre tranqüila). Os objetivos da terapêutica seriam deter o mais precocemente possível o transcurso temporal da doença, evitando seu agravamento ou procurando minimizá-lo, ou ainda tentando reduzir o impacto de eventuais limitações dela decorrentes. Cada etapa desta corresponde a um momento da história natural das doenças, definindo níveis de prevenção (primário, secundário, terciário). Essa observação assinala a subordinação, na Biomedicina, das práticas curativas e preventivas a um mesmo referencial teórico geral.

De acordo com sua resolutividade, a terapêutica poderia ser dividida segundo outra taxonomia:

- Sintomática, produzindo apenas a supressão de sintomas, usualmente porque não há outras medidas mais eficazes a se tomar;

- Paliativa, procurando limitar danos e/ou desconforto, como, por exemplo, no seccionamento cirúrgico dos feixes espinotalâmicos 
(cordotomia) em portadores de neoplasias crônicas intratáveis como forma de impedir que sintam dor;

- Suportiva, dirigida à manutenção das condições gerais do paciente, como a administração de nutrientes por via endovenosa (nutrição parenteral total) àqueles que não podem consumir alimentos pelos meios usuais, ou na assistência ventilatória a pacientes com problemas respiratórios, ou ainda nas várias técnicas de reabilitação física;

- Etiológica, que removeria a causa original da doença, como, por exemplo, na administração de antibióticos em infecções bacterianas.

Essa relação apresenta em ordem inversa de valorização os tipos de terapêutica: idealmente, o objetivo final das técnicas terapêuticas seria sempre remover as causas das doenças e, portanto, as próprias doenças. De qualquer modo, nunca é demais citar uma frase de Canguilhem (1982, p. 185) neste contexto: "[...] a terapêutica é uma técnica de instauração ou de restauração do normal, cujo fim escapou à jurisdição do saber objetivo, pois é a satisfação subjetiva de saber que uma norma está instaurada". Ou seja, retomando uma terminologia já empregada anteriormente, a terapêutica é a expressão maior da "arte" ou ofício de curar, o que leva a tensões importantes com o projeto de uma Medicina científica.

\section{Observações Finais}

A Biomedicina, apesar de sua pujança técnica (ou talvez por causa dela), vem sendo criticada sistemática e severamente por suas mazelas. É evidente que essa situação tem uma miríade de determinantes, como as opções de política econômica, o impacto da organização dos setores público e privado na assistência à saúde, as deficiências na formação profissional, os interesses econômicos mais ou menos explícitos das indústrias farmacêutica e de equipamentos médicos, que extrapolam em muito o escopo deste trabalho.

Insisti, em vários pontos deste texto, no caráter implícito de uma série de concepções que dominam até certo ponto essa racionalidade médica, ao mesmo tempo em que não são usualmente objeto de reflexão crítica justamente por seu caráter implícito. Seria um ato de voluntarismo ingênuo atribuir todas as dificuldades apontadas acima às características intrínsecas dessa racionalidade, mas, de qualquer modo, esta é também moldada por essas contingências, e se 
não é possível apontá-la como determinante primordial dos impasses que a assistência à saúde atravessa, decerto há uma articulação coerente entre esses determinantes e a lógica interna da prática por eles determinada. Esta lógica tem, no meu entender, consequiências concretas na determinação de um modelo de atenção que avaliza, de alguma forma, uma série de características, como o uso excessivo de exames complementares, a desvalorização da subjetividade do paciente (e do próprio médico), a farmacologização excessiva, que configuram uma propensão iatrogênica intrínseca que não pode ser chamada de "distorção".

Não pretendo com isto questionar a legitimidade ou mesmo a eficácia da prática médica, até porque, como já registrei anteriormente aqui, a relação teoria/prática em Medicina é bem mais contingente do que se poderia supor. Efetivamente, espero que a exposição dos impasses conceituais, teóricos e metodológicos do corpo disciplinar que em tese a fundamenta contribua de algum modo para uma reflexão crítica que recupere o papel central dos aspectos especificamente humanos (o que chamei há pouco de "arte de curar") desta mesma prática, para que não sigamos tendo, como aponta Clavreul (1983), em vez de uma relação intersubjetiva de médicos e pacientes, as relações estéreis 3/4 e iatrogênicas 3/4 entre instituições e doenças.

\section{Referências}

ALMEIDA FILHO, N. Epidemiologia sem números. Rio de Janeiro: Campus, 1989.

ACKERNECHT, E. W. La médicine hospitaliere à Paris: 1794-1848. Paris: Payot, 1986.

ALMEIDA, E. Medicina hospitalar, medicina extra-hospitalar: duas medicinas? Dissertação (Mestrado em Saúde Coletiva) - Programa de Pósgraduação em Saúde Coletiva, Instituto de Medicina Social, Universidade do Estado do Rio de Janeiro, 1988.

BACHELARD, G. A epistemologia. Lisboa: Edições 70, 1977.

BALINT, M O médico, seu paciente e a doença. Rio de Janeiro: Ateneu, 1975.

BLANK, N. O raciocínio clínico e os equipamentos médicos. Dissertação (Mestrado em Medicina Social) - Programa de Pós-graduação em Medicina 
Social, Instituto de Medicina Social, Universidade do Estado do Rio de Janeiro, 1985.

BURTT, E. A. As bases metafísicas da ciência moderna. Brasília: UnB, 1983.

CAMARGO JR., K. R. (Ir)Racionalidade médica: os paradoxos da clínica. Dissertação (Mestrado em Saúde Coletiva) - Programa de Pós-graduação em Saúde Coletiva, Instituto de Medicina Social, Universidade do Estado do Rio de Janeiro, 1990.

CAMARGO JR., K. R. A medicina ocidental contemporânea. Cadernos de Sociologia, Porto Alegre v. 7, p. 129-150, dez. 1995.

CANGUILHEM, G. O normal e o patológico. Rio de Janeiro: Forense Universitária, 1982.

CANGUILHEM, G. O que é uma ideologia científica? In: . Ideologia e racionalidade nas ciências da vida. Lisboa: Edições 70, 1977.

CLAVREUL, J. A ordem médica. São Paulo: Brasiliense, 1983.

FOUCAULT, M. Las formaciones discursivas. In: . La arqueologia del saber. Mexico: Siglo Veintiuno, 1972.

FOUCAULT, M. O nascimento da medicina social. In: FOUCAULT, M., Microfisica do poder. Rio de Janeiro: Graal, 1981.

FOUCAULT, M. O nascimento do hospital. In: . Microfisica do poder. Rio de Janeiro: Graal, 1981.

GINZBURG, C. Sinais: raízes de um paradigma indiciário. In: . Mitos, emblemas, sinais. São Paulo: Cia. das Letras, 1989.

GRMEK, M. La réception du De Sedibus de Morgagni en France au 18è. siec1e. Dixhuitieme Siecle, n. 23, p. 59-73, 1991.

HALL, A. R A revolução na ciência, 1500-1750. Lisboa: Edições 70, 1988.

KLEINENBAUM, D. G. et alii. Epidemiologic research. Belmont, CA: Lifetime Learning Publications, 1982.

LEAVELL, H.; CLARK, E. G. Medicina preventiva. São Paulo: McGrawHill do Brasil, 1976. 
LILLIENFELD, D. Foundations of Epidemiology. New York: Oxford University Press, 1980.

LOWY, I. Ludwik Fleck e a presente história das ciências. História, Ciências, Saúde - Manguinhos, Rio de Janeiro, v. 1, n. 1, p. 7-18, 1994.

LUZ, M. T. Introdução. In: LUZ, M. T. et al. (Org.). Primeiro seminário Projeto Racionalidades Médicas. Rio de Janeiro, IMS-UERJ, 1992. Mimeo.

PINTO, P. G. H. R. Saber ver: recursos visuais e a formação médica. Dissertação (Mestrado em Saúde Coletiva) - Programa de Pós-graduação em Saúde Coletiva, Instituto de Medicina Social, Universidade do Estado do Rio de Janeiro, 1997.

PLASTINO, C. Os horizontes de Prometeu. Considerações para uma crítica da modernidade. Physis - Revista de Saúde Coletiva, Rio de Janeiro, v. 6, n. 1/2,p. 195-216, 1996.

FLECK, L. Genesis and development of a scientific facto Chicago: University of Chicago Press, 1979.

RODRIGUES, R. D. A crise da Medicina: prática e saber. Rio de Janeiro, IMS-UERJ, 1979.

SACKETT, D., HAYNES, B.; TUGWELL, P. Clinical epidemiology. Boston: Little, Brown \& Co., 1985.

SAYD, J. D. Mediar, medicar, remediar. Terapêutica na Medicina contemporânea: o pensamento médico brasileiro Tese (Doutorado em Saúde Coletiva) - Programa de Pós-graduação em Saúde Coletiva, Instituto de Medicina Social, Universidade do Estado do Rio de Janeiro, 1995.

\section{NOTAS}

\footnotetext{
${ }^{1}$ Este trabalho é um desdobramento de um texto originalmente publicado em Camargo Jr. (1995). A ampliação deste trabalho se deve em muito aos próprios desenvolvimentos do Projeto Racionalidades Médicas e a sugestões do professor Mirko Grmek, quando de sua estada mais recente no Brasil. Publicado em Physis, v. 7, n. 1, p. 45-62, 1997.

${ }^{2}$ Doutor em Saúde Coletiva, professor adjunto do Departamento de Planejamento e Administração em Saúde do IMS/UERJ. E-mail: kenneth@uerj.br.
} 
Kenneth Rochel de Camargo Jr.

${ }^{3}$ Desenvolvi esta asserção em Camargo Jr. (1990).

${ }^{4}$ Sobre as implicações de uma razão supostamente ao largo da crítica, ver Plastino (1996).

${ }^{5} \mathrm{O}$ termo proposto por Bachelard (1977, p. 72-73) se refere à característica da ciência contemporânea de produzir fenômenos, mais do que relatá-los.

${ }^{6}$ Note-se aqui a sutileza do deslizamento de "transtorno" para "doença".

${ }^{7}$ Para uma crítica deste conceito, ver Almeida Filho (1989, p. 19).

${ }^{8}$ Um exemplo de sofisticação tecnológica é a tomografia por ressonância magnética nuclear. A incorporação acelerada das novas tecnologias na Medicina talvez só encontre paralelo na indústria militar.

${ }^{9}$ Aqui se daria o ponto de ligação mais estreito com a Epidemiologia.

10 “Caso se possa descrever, entre certo número de enunciados, semelhante sistema de dispersão, no caso em que entre os objetos, os tipos de enunciação, os conceitos, as eleições temáticas, se possa definir uma regularidade (uma ordem, correlações, posições em funcionamento, transformações), se dirá, por convenção, que se trata de uma formação discursiva [...]".

${ }^{11}$ Embora tenham existido importantes desenvolvimentos na Fisiologia que datam de antes desse período, estes não foram incorporados de modo uniforme ou mesmo importante na prática médica. Ackernecht, por exemplo, cita que Cabanis, importante e influente médicofilósofo para a geração de médicos que virtualmente criou a anátomo-clínica em Paris, desprezava a contribuição de outras disciplinas científicas para a Medicina, por não trazerem qualquer resultado prático (ACKERNECHT, 1986, p. 20-21).

${ }^{12}$ Foucault, ao final de $O$ Nascimento do Hospital, conclui: "O indivíduo e a população são dados simultaneamente como objetos de saber e alvos de intervenção da medicina, graças à tecnologia hospitalar. [...] A Medicina que se forma no século XVIII é tanto uma medicina do indivíduo quanto da população" (FOUCAULT, 1981). Lillienfeld, por sua vez, inicia seu livro com a seguinte frase: "A Epidemiologia ocupa-se com os padrões de ocorrência de doença em populações humanas e dos fatores que influenciam estes padrões” (LILLIENFELD, 1980), frase que Kleinenbaum et al. (1982, p. 20) repetem quase literalmente: “epidemiologia pode ser vista simplesmente como o estudo de doença e saúde em populações humanas”. Acredito que a convergência entre as citações fala por si só.

${ }^{13}$ Para uma análise detalhada do equipamento na diagnose e suas implicações para a prática da Medicina, ver Blank (1985). 
${ }^{14}$ Para uma descrição mais detalhada e bem humorada desta característica, ver Sackett (1985, p. 6-15).

15 “[...] uma comunidade de pessoas intercambiando idéias mutuamente ou mantendo interação intelectual; também veremos por implicação que esta também provê o 'suporte' especial para o desenvolvimento histórico de qualquer campo do pensamento, bem como do nível de cultura e conhecimento dados" (FLECK, 1979, p. 39).

16 “[...] uma construção definida do pensamento, e até mais; [...] a totalidade da preparação ou disponibilidade intelectuais para uma forma particular de ver e agir em vez de qualquer outra" (FLECK, 1979, p. 64).

${ }^{17}$ Veja-se a discussão sobre a metafísica oculta do positivismo, na nota 10. Esta visão é incutida desde cedo nos futuros médicos, como parte do próprio ensino. Ver Pinto (1997).

${ }^{18}$ Isto foi denominado por Balint (1975) de "eliminação através de exames apropriados”. Ainda que se possa discordar de algumas das interpretações desse autor, sua obra traça um retrato bastante fiel de algumas das fragilidades e hesitações do saber e da prática da medicina. Ainda sobre o tema, ver Almeida (1988); Blank. (1985) e Camargo Jr. (1990).

\section{ABSTRACT}

\section{The Biomedicine}

The theoretical construction of nosologic categories plays a major role in medical rationality. Structured upon scientific models originated from the development of classical physics, medical knowledge is, however an irregular aggregate of disciplines where many of its fundamental notions are implicit, leading to the production of contradictions that cannot be overcome, both intemally and in its relations to clinics. This paper analyses in detail some of the preconceptions of this rationality, attempting to outline the obstacles that they produce, which in turn hamper the fulfillment of the ethical goals of the therapeutic practices.

Key words: Epistemology; medical rationality; history of medicine. 